\title{
VIRGINS ARE LOUDER: THE EFFECT OF MATING ON ACOUSTIC Signaling IN SAgEbRUSh CRICKETS
}

\author{
W. ANDY SNEDDEN $\downarrow$ MICHAEL D. GREENFIELD \\ DEPARTMENT OF ENTOMOLOGY $\downarrow$ UNIVERSITY OF KANSAS $\uparrow$ LAWRENCE
}

\section{$\uparrow \quad$ ABSTRACT}

Female sagebrush crickets, Cyphoderris strepitans, feed on the male's hind wings during copulation. Because removal of hind wing material during mating may alter male acoustic signal characteristics and account for a virgin male mating advantage (Morris et al. 1989; Snedden, in press) we recorded virgin and mated males in the field, and virgins before and after surgical excision of a portion of the hind wings. We found no significant differences in signal spectral characteristics or pulse rate between virgin and mated males following hindwing excision. However, the signal amplitude of laboratory recorded virgins was greater than that of mated males, and song amplitude was reduced in manipulated males. In contrast, signal amplitude was lower in field recorded virgins than mated males.

\section{$\downarrow \quad$ INTRODUCTION}

The conspicuous acoustic signals of many orthopteran insects function both in inter-male interactions and mate attraction and courtship (reviewed by Cade, 1979). Much recent interest has centered on the potential information content of such sexual advertisement signals and their role in the operation of sexual selection. If variation in some aspect of male quality exists, whether it be genetic or in direct benefit provided, then females should be subject to strong selection pressure to make appropriate choices among potential mates. Information that might provide females a means of long range assessment regarding male genetic or gift quality could be available in the spectral or temporal aspects of male sexual advertisement acoustic signals.

In many acoustic insects, females receive direct benefit from males at mating in the form of nuptial gifts, such as spermatophores or glandular secretions (see Thornhill and Alcock, 1983). Such nuptial gifts can be an important component of female fitness (e.g. Gwynne, 1984). and thus individuals who discriminate against males providing inadequate or inferior gifts should be at a selective advantage. Acoustic advertisement signals may yield information about the signaler's size and or vigor that predicts the quality of his gift, and thus provide females with mate assessment cues. As acoustic signals may provide such information at some distance, females using this information could avoid the energetic and potential predation costs associated with traveling to an inappropriate mating partner. In the acoustic Orthoptera, aspects of song have been shown to vary with male age (Hedrick, 1986; Ritchie et al. 1995) and size (Latimer and Schatral, 1986; Latimer and Sipple, 1987; Wedell and Sandberg, 1995). Male body mass is correlated with gift size in several species of katydids (e.g. Wedell, 1993) and thus variation in the signal correlated with male mass could indicate gift size.

Sagebrush crickets, Cyphoderris strepitans, are members of an ancient insect lineage, the Haglidae, and are found only in the mountains of Wyoming and Colorado, USA (Morris and Gwynne, 
1979). Each evening during the early spring mating season, males emerge from the soil litter, climb calling perches, and produce a rhythmic song which functions in the attraction of females (Snedden and Irazuzta, 1994) and in male spacing behavior (Sakaluk et al. 1995). The song is an almost pure tone $(13 \mathrm{kHz})$ sustained trill punctuated by short silent intervals. During copulation, the female feeds on the male's fleshy hind wings and also ingests the resultant flow of haemolymph (Dodson et al. 1983; Morris et al. 1989; Sakaluk and Snedden, 1990; Snedden and Sakaluk, 1992). Males may thus provide females with a direct benefit at mating. Although the amount of hind wing material consumed at mating is variable (pers. obser.), males' hind wings are permanently damaged by wing-feeding and this may impair their ability to further provide an adequate nuptial gift.

Morris et al. (1989) and Snedden (in press) reported a virgin male mating advantage in this species whereby virgin males obtained more matings than predicted by a null model of random mating. Morris et al. (1989) suggested that this virgin male mating advantage may result from differences in the attractiveness of the signal of virgin versus mated males. They suggested that female consumption of hind wing material during mating may change the acoustic impedance of the air mass under the sound radiating fore wings, and that this could alter song characteristics (see also Stephen and Hartley, 1995). We tested this hypothesis by examining 1) the temporal, spectral, and amplitude characteristics of the song of virgin and mated males recorded in the field and under controlled laboratory conditions, and 2) the signal characteristics of virgin males before and after surgical excision of a portion of their hind wings.

\section{$\uparrow \quad$ METHODS}

This study was conducted during late May and early June 1995 in Grand Teton National Park, Wyoming, USA. We recorded males in the field at Deadman's Bar Lower Site; males used in laboratory recordings were collected at Deadman's Bar Upper Site (Snedden and Sakaluk, 1992; Snedden, in press).

\section{FIELD RECORDINGS}

Males were captured and individually marked using a numbered plastic tag glued to the pronotum. Male mating status, virgin or previously mated, was determined by examining the hind wings for evidence of mating activity. Males were recorded using a Shure BG 4.0 condenser microphone and Casio DA-7 DAT recorder. We recorded 8 virgins and 10 mated males. Sound pressure level (SPL) $\left(\begin{array}{llllll}0 & \mathrm{~dB} & \text { re } & 20 & \mu \mathrm{Pa}\end{array}\right)$ was determined for a sample of 18 males using a General Radio 1982 SPL meter (detection = peak; weighting $=$ flat; filter $=16 \mathrm{kHz}$ ). Because males often cease calling when disturbed it was not possible to measure SPL for all males at a standard distance and orientation (i.e. $10 \mathrm{~cm}$, dorsal aspect). We therefore measured SPL at $1 \mathrm{~m}$ from each male at $0,90,180$, and $360^{\circ}$ in the horizontal plane. This also allowed us to average any effect of the animal's posture and excess attenuation on SPL. Temperature at each male's calling perch was determined using a Bailey ${ }^{\circ}$ BAT-12 electronic thermometer.

\section{LABORATORY RECORDINGS}

Males used in laboratory recordings were individually housed in plastic containers containing soil, provided a diet of apple, and maintained at the ambient L:D cycle. The temperature regime within the housing facility approximated that of ambient outdoor conditions. Prior to each evening's recording, males were placed into screen cages suspended from the ceiling by fine twine such that males were separated by approximately $1 \mathrm{~m}$ and were at least $1 \mathrm{~m}$ from the ceiling and nearest wall. Recordings were conducted between approximately 1900 and 2400 hrs., the period during which animals are typically found calling in the field. We used the same recording and SPL equipment and settings as in the field study. SPL measurements were taken at $10 \mathrm{~cm}$, dorsal aspect. For a sample of 5 males we determined SPL at $10 \mathrm{~cm}$ from the dorsal, ventral, lateral, anterior, and posterior aspect.

To examine directly the effect of wing feeding on signal characteristics we recorded virgin males 
before and after surgical excision of a portion of the hind wings typical of that consumed by females during copulation (pers. obser.). The portion of the hind wings was removed with micro-scissors the day prior to the second recording. Four manipulated males and 5 control males, whose hind wings were not removed but who were similarly handled, were used in this experiment. Unmanipulated males were used to control for possible age effects on song characteristics.

Signals were digitized at a sample rate of $50 \mathrm{kHz}$ and analyzed on a PC using SoundFX ${ }^{\circ}$ and custom software. We determined 1) peak frequency, 2) peak amplitude (SPL), and 3) pulse rate (pulses per second). Pulse rate was standardized for the effect of temperature. We also determined each signal's $Q$ value, a measure of tonal purity, which was determined as; peak frequency divided by the frequency band width at half peak energy output (after Ewing, 1989).

\section{$\uparrow \quad$ RESULTS}

\section{LABORATORY RECORDINGS}

Mean ( \pm SD) SPL measures from the dorsal, ventral, lateral, anterior, and posterior aspects are in Table 1.
Table 1. Mean ( \pm SD) SPL from 5 males measured at various aspects.

\begin{tabular}{lcc}
\hline \multicolumn{1}{|c}{ Aspect } & Mean & SD \\
\hline Dorsal & 107.2 & 1.2 \\
Ventral & 101.6 & 1.3 \\
Lateral & 104.5 & 0.8 \\
Anterior & 103.5 & 2.0 \\
Posterior & 102.8 & 1.0 \\
\hline
\end{tabular}

There was no significant difference in pulse rate, peak frequency, or $Q$ value between manipulated males prior to and after removal of the hind wings, between mated males and virgin males, or between control males before and after 'treatment' (paired ttests, all $p>0.05$; Table 2). There was no significant difference in SPL (paired t-test; $t=0.719 ; p>0.050)$ between control virgins before and after 'treatment'. However, there was a significant difference in SPL between manipulated males prior to and after hind wing excision (paired $t$-test; $t=2.21 ; p=0.033$ ), and between virgin and mated males ( $t$-test; $t=-5.702 ; p<0.001$ ). The mean SPL difference between manipulated males before and after treatment was $0.3 \mathrm{~dB}$, and $1.6 \mathrm{~dB}$ between virgins and mated males.

Table 2. Mean $( \pm S D)$ temporal, spectral, and amplitude characteristics of laboratory recorded virgin and mated males, males prior and subsequent to manipulation of their hind wings, and control males.

\begin{tabular}{lccccc}
\hline \multicolumn{1}{|c}{ Group } & n & $\begin{array}{c}\text { Pulse Rate } \\
\left(\text { pulses }^{-3}\right)\end{array}$ & $\begin{array}{c}\text { Peak Frequency } \\
(\mathbf{k H z})\end{array}$ & $\mathbf{Q}$ & $\begin{array}{c}\text { SPL } \\
(\mathbf{d B})\end{array}$ \\
\hline Virgin & 3 & $40.6 \pm 1.4$ & $12.7 \pm 0.8$ & $19.6 \pm 8.1$ & $107.6 \pm 0.9^{\mathrm{a}}$ \\
Mated & 3 & $39.8 \pm 1.9$ & $12.8 \pm 0.9$ & $24.5 \pm 9.2$ & $106.0 \pm 0.9^{\mathrm{a}}$ \\
Intact Hind Wings & 4 & $38.7 \pm 1.8$ & $12.8 \pm 0.9$ & $17.8 \pm 6.4$ & $107.2 \pm 1.2^{\mathrm{a}}$ \\
Hind Wings Removed & 4 & $40.4 \pm 1.4$ & $13.0 \pm 0.9$ & $25.3 \pm 11.0$ & $106.9 \pm 1.2^{\mathrm{b}}$ \\
Control 'before' & 5 & $41.4 \pm 3.8$ & $12.4 \pm 0.9$ & $15.9 \pm 7.5$ & $107.4 \pm 1.1$ \\
Control 'after' & 5 & $39.0 \pm 1.9$ & $12.8 \pm 0.9$ & $25.8 \pm 9.6$ & $107.3 \pm 1.4$ \\
\hline Means with the same letter are significantly different $(\mathrm{p}<0.05)$ & & \\
\hline
\end{tabular}




\section{FIELD RECORDINGS}

There was no significant difference (t-tests, all $\mathrm{p}<0.05$ ) between virgin and mated males in pulse rate, peak frequency, or $Q$ value (Table 3 ). There was a significant difference between virgin and mated males in signal SPL ( $t$-test, $t=2.27$, $\mathrm{p}<0.050$ ).

\section{$\uparrow \quad$ DISCUSSION}

We did not detect any significant spectral or temporal changes in the signal characteristics of male sagebrush crickets that were associated with mating and thus hind wing feeding. However, our laboratory recordings revealed that virgins and males prior to hind wing excision were louder than mated males or post-manipulation experimental males, respectively. Though significant, these differences in sound pressure level were small. Nevertheless, as SPL scales logarithmically and broadcast area (the area in which a male's signal SPL equals or exceeds the female auditory threshold) scales geometrically, the observed differences may influence mate attraction. For example, the difference in SPL between males prior to and after excision of the hind wings was $0.3 \mathrm{~dB}$ (measured at $10 \mathrm{~cm}$ ). Using an average value of female auditory threshold of $65 \mathrm{~dB}$, and considering only geometric spreading loss $(-6 \mathrm{~dB}$ for distance doubled), this translates into a difference in broadcast area of approximately $37 \mathrm{~m}^{2}$. Laboratory recorded virgins were on average $1.6 \mathrm{~dB}$ louder than mated males which represents a $170 \mathrm{~m}^{2}$ larger broadcast area. Even if females orient to males at random, the size of a male's broadcast area will be directly related to the number of females attracted, and thus virgins will have a mating advantage.
The results of our field recordings also showed no difference in the spectral or temporal characteristics of virgin versus mated male signals. We did find a significant difference in SPL; in this case mated males were louder. Our laboratory recordings suggest that removal of hind wing material results in a decrease in SPL. We do not suggest that the opposite is the case in the field, but rather, that males recorded in the field as virgins were such because they have a low signal SPL. Males used in the laboratory recordings were collected early in the mating season and thus many of these virgins would have probably mated had they remained in the field. Our field recordings were conducted toward the end of the mating season when about $67 \%$ of males had mated. A previous study of male lifetime mating success in sagebrush crickets (Snedden, in press) showed that between $62 \%$ (1991) and $72 \%$ (1992) of males obtain matings. Thus, the virgins we recorded at the end of the season probably did not mate subsequent to recording. We suggest that the higher SPL of mated males observed in the field was not a result of mating having affected the SPL of their signals but that those animals who remain unmated at the end of the season were unable to attract mates because of the low SPL of their songs.

Could the observed difference in SPL between virgins and mated males account for the virgin male mating advantage reported for this species? The large difference in broadcast area that results from small differences in SPL is likely to contribute to the virgin male mating advantage, even if females choose mates at random. However, mating may also reduce energy reserves required for calling as mated males are less able to sustain nightly calling (Sakaluk et al. 1987; Sakaluk and Snedden, 1990) and are unable to attend the chorus

Table 3. Mean ( $\pm S D$ ) temporal, spectral, and amplitude characteristics of field recorded virgin and mated males. Pulse rate is standarized to $10^{\circ} \mathrm{C}$.

\begin{tabular}{lcccc}
\hline $\begin{array}{l}\text { Mating } \\
\text { Status }\end{array}$ & $\begin{array}{c}\text { Pulse Rate } \\
\left(\text { pulses }^{-5}\right)\end{array}$ & $\begin{array}{c}\text { Peak Frequency } \\
(\mathbf{k H z})\end{array}$ & $\mathbf{Q}$ & $\begin{array}{c}\text { SPL } \\
\text { (dB) }\end{array}$ \\
\hline Virgin $(\mathrm{n}=8)$ & $20.5 \pm 1.8$ & $13.5 \pm 0.9$ & $38.9 \pm 26.2$ & $77.7 \pm 2.01^{*}$ \\
Mated $(\mathrm{n}=10)$ & $20.2 \pm 1.0$ & $13.1 \pm 0.6$ & $22.2 \pm 12.7$ & $79.8 \pm 1.93^{*}$ \\
\hline
\end{tabular}

*significant difference $(\mathrm{p}<0.05)$ 
for many nights during the short breeding season (pers. obser.). Additionally, males are short-lived as adults and the short breeding season makes it unlikely that many males are able to secure more than one mating and about one third of males do not mate at all (Snedden, in press).

That we did not find a difference in spectral characteristics associated with hind wing feeding was surprising. However, Stephen and Hartley (1995) recently suggested that some crickets can monitor their signal frequency and 'keep in tune' by adjusting the position of their fore wings relative to their abdomen. Although counter to the conventional wisdom of cricket signal production mechanisms, should this prove true it may be that sagebrush crickets can monitor their signal and adjust the position of their fore wings to compensate for the effects of wing feeding on their signal. Experiments which examine the signal of males that have their hind wings removed and are also rendered deaf could resolve this question.

\section{ACKNOWLEDGMENTS}

H. Harlow and the UW-NPS Research Center provided logistic support. H. Harlow, T. Harlow and Z. Harlow assisted in the field. This study was supported by grants from NSF and the UW-NPS Research Center.

\section{LITERATURE Cited}

Cade, W.H. 1979. The evolution of alternative male reproductive strategies in field crickets. In Blum, M.S. and Blum., N.A. (eds.), Sexual Selection and Reproductive Competition in Insects, Academic Press, New York, pp. 343-379.

Dodson, G.N., G.K. Morris, and D.T. Gwynne. 1983. Mating behavior of the primitive orthopteran genus Cyphoderris (Haglidae). In Gwynne, D.T. and Morris, G.K., (eds.), Orthopteran Mating Systems: Sexual Competition in a Diverse Group of Insects, Westview Press, Boulder, Colorado, pp. 305-318.

Ewing, A.W. 1989. Arthropod Bioacoustics: Neurobiology and Behaviour, Edinburgh Univ. Press, Edinburgh.
Gwynne, D.T. 1984. Courtship feeding increases female reproductive success in bushcrickets. Nature 307:361-363.

Hedrick, A.V. 1986. Female preferences for male calling bout duration in a field cricket. Behav. Ecol. Sociobiol. 19:73-77.

Latimer, W. and A. Schatral. 1986. Information cues used in male competition by Tettigonia cantans (Orhtoptera: Tettigoniidae). Anim. Behav. 34:162-168.

Latimer, W. and M. Sipple. 1987. Acoustic cues for female choice and male competition in Tettigonia cantans. Anim. Behav. 35:887900.

Morris, G.K. and D.T. Gwynne. 1979. Geographical distribution and biological observations of Cyphoderris (Orthoptera: Haglidae) with a description of a new species. Psyche 85:147-167.

Morris, G.K., D.T. Gwynne, D.T. Klimas, and S.K. Sakaluk. 1989. Virgin male mating advantage in a primitive acoustic insect (Orthoptera:Haglidae). J. Insect Behav. 2:173-185.

Ritchie, M.G., I.D. Couzin, and W.A. Snedden. 1995. What's in a song? Female bushcrickets discriminate against the song of older males. Proc. Roy. Soc. Lond. B 262:21-27.

Sakaluk, S.K., G.K. Morris, and W.A. Snedden. 1987. Mating and its effect on acoustic signalling behaviour in a primitive orthopteran, Cyphoderris strepitans (Haglidae): the cost of feeding females. Behav. Ecol. Sociobiol. 21:173-178.

Sakaluk, S.K., and W.A. Snedden. 1990. Nightly calling durations of male sagebrush crickets, Cyphoderris strepitans: size, mating and seasonal effects. Oikos 57:153160.

Sakaluk, S.K., W.A. Snedden, K.A. Jacobson, and A.K. Eggert. 1995. Sexual competition in sagebrush crickets: must males hear calling rivals? Behav. Ecol. 6:250-257. 
Snedden, W.A. (in press). Lifetime mating success in male sagebrush crickets: sexual selection constrained by a virgin male mating advantage. Anim. Behav.

Snedden, W.A., and S. Irazuzta. 1994. Attraction of female sagebrush crickets to male song: the importance of field bioassays. J. Insect. Behav. 7:233-236.

Snedden, W.A., and S.K. Sakaluk. 1992. Acoustic signalling and its relation to male mating success in sagebrush crickets. Anim. Behav. 44:633-639.

Stephen, R.O., and J.C. Hartley. 1995. Sound production in crickets. J. Exp. Biol. 198:2139-2152.
Thornhill, R., and J. Alcock. 1983. The evolution of insect mating systems., Harvard University Press, Cambridge, Massachusetts.

Wedell, N. 1993. Mating effort or parental investment:incorporation rate and cost of male donations in the wartbiter. Behav. Ecol. Sociobiol. 32:239-246.

Wedell, N., and T. Sandberg. 1995. Female preference for large males in the bushcricket Requena sp. 5 (Orthoptera: Tettigoniidae). J. Insect Behav. 8:513-522. 